\title{
Incidence of abdominal obesity and its risk factors among Tehranian adults
}

\author{
Maryam Barzin ${ }^{1}$, Zahra Piri ${ }^{1}$, Sara Serahati ${ }^{1}$, Majid Valizadeh ${ }^{1}$, Fereidoun Azizi ${ }^{2}$ and \\ Farhad Hosseinpanah ${ }^{1, *}$ \\ 'Obesity Research Center, Research Institute for Endocrine Sciences, Shahid Beheshti University of Medical Science, \\ PO Box 19395-4763, Tehran, Islamic Republic of Iran: ${ }^{2}$ Endocrine Research Center, Research Institute for Endocrine \\ Sciences, Shahid Beheshti University of Medical Science, Tehran, Islamic Republic of Iran
}

Submitted 18 December 2017: Final revision received 4 May 2018: Accepted 20 June 2018: First published online 17 September 2018

\begin{abstract}
Objective: Abdominal obesity (AO) is a relative risk factor for cardiovascular events. We aimed to determine the 6-year incidence of $\mathrm{AO}$ and its risk factors among Tehranian adults.

Design/Setting/Subjects: In this population-based cohort study, non-abdominally obese participants, aged $\geq 20$ years, were followed for incidence of $\mathrm{AO}$. Cumulative incidence and incidence rate of $\mathrm{AO}$ were calculated for each sex. Cox proportional hazard regression was used to determine the association of potential risk factors including age, BMI, dysmetabolic state, smoking, marital status, educational level and physical activity (PA).

Results: A total of 5044 participants (1912 men) were followed for a median of 6 years. Mean age was 37.7 (SD 13.5) years at baseline, with mean BMI of 24.3 (SD $3 \cdot 1$ ) $\mathrm{kg} / \mathrm{m}^{2}$ (men, $23 \cdot 0$ (sD $2 \cdot 4$ ) $\mathrm{kg} / \mathrm{m}^{2}$; women, $25 \cdot 0$ (sD $3 \cdot 2$ ) $\mathrm{kg} / \mathrm{m}^{2}$ ). During followup, 3093 (1373 men) developed AO with total cumulative incidence of $76 \cdot 02$, 83.59 and $70.90 \%$, for the whole population, men and women, respectively. Corresponding incidence rates were 96.0, $138 \cdot 7$ and $77 \cdot 1$ per 1000 person-years. The highest incidence rate was observed during their $30 \mathrm{~s}$ and $50 \mathrm{~s}$, in men and women, respectively. Subjects with dysmetabolic state in both sexes, married women, men with lower PA and higher educational levels at baseline were at higher risk of $\mathrm{AO}$.

Conclusions: The incidence of $\mathrm{AO}$ is high among Tehranian adults, especially in young men. The risk factors for developing AO should be highlighted to halt this growing trend of $\mathrm{AO}$.
\end{abstract}

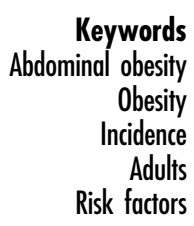

Obesity has become a global health burden owing to its complications such as hypertension, type 2 diabetes, dyslipidaemia, coronary artery disease, stroke and cancer $^{(1,2)}$. Overweight and obesity affected over 600 million adults in 2014 worldwide, a rate expected to be about 1.2 billion in $2030^{(3)}$. Commonly BMI is used to determine body fat, but it is not a strong predictor of total body fat and subsequently the risk of CVD. In contrast, waist circumference (WC) as a measure of abdominal obesity (AO) identifies the risk of cardiometabolic disease more precisely than $\mathrm{BMI}^{(4)}$. A population-based study in the USA reported that $7 \cdot 6 \%$ of adults aged $\geq 20$ years had $\mathrm{AO}$ and $33.7 \%$ had abnormal waist-to-hip ratio in $2012^{(5)}$. The importance of intervention and control of $\mathrm{AO}$ as a universal concern is clarified by a study in the National Health and Nutrition Examination Survey (NHANES) framework, which revealed a significant increase in overall AO prevalence from $46.4 \%$ in $1999-2000$ to $54 \cdot 2 \%$ in $2011-2012$ within a population consisting of men, women, nonHispanic whites, non-Hispanic blacks and Mexican Americans $^{(6)}$. In the Iranian adult population, $\mathrm{AO}$ is more prevalent in women than in men and in older ages in both sexes $^{(7)}$. Based on data from the Tehran Lipid and Glucose Study (TLGS) through phases 1 to 4 (1999 to 2011), AO prevalence increased from 52 to $78 \%$ in men and from 44 to $66 \%$ in women ${ }^{(8)}$. Incidence studies are needed to identify the high-risk individuals for AO. Since $\mathrm{AO}$ is a highly relative risk factor for cardiovascular events ${ }^{(9,10)}$, focus on a cohort study would help clarify of the incidence and risks of $\mathrm{AO}$. We aimed to explore the incidence of $\mathrm{AO}$ and its risk factors in an adult Tehranian population in the TLGS over a median 6 years of follow-up. 


\section{Methods}

\section{Study population}

Using the data of participants of the TLGS, a dynamic prospective population-based study, the present study was conducted on a representative sample of the Tehranian population with the aim of determining the prevalence and risk factors of non-communicable diseases. Details of study protocol are available elsewhere ${ }^{(11,12)}$. To summarize, the TLGS has two major components: (i) a cross-sectional prevalence study of non-communicable disease (1999-2001) and associated risk factors; and (ii) prospective follow-up studies at approximately 3-year intervals. About 15005 residents participated in the first examination cycle (1999-2001) and another 3555 residents were first examined at the second examination cycle (2002-2005). Of these 18560, a total of 12808 participants aged $\geq 20$ years at baseline were selected for the current study. Participants with AO ( $n$ 5524), BMI below $18.5 \mathrm{~kg} /$ $\mathrm{m}^{2}$ ( $n$ 322), pregnancy ( $\left.n 98\right)$, corticosteroid consumption ( $n$ 245) at baseline and those without any follow-up data ( $n$ 1575) were excluded, leaving 5044 participants to be followed up to 2014.

All participants provided written, informed consent. The protocol of the present study, conducted in accordance with principles of the Declaration of Helsinki, was approved by the ethics committee of the Research Institute of Endocrine Sciences of Shahid Beheshti University of Medical Sciences.

\section{Clinical and laboratory measurements}

Using a pre-tested questionnaire, a trained interviewer collected information which included baseline demographic information, family history of diabetes, past medical history of CVD, drug use and smoking behaviour. Weight was measured with participants minimally clothed without shoes, using digital scales (Seca 707; Seca Corporation, Hanover, MD, USA; range $0 \cdot 1-150 \mathrm{~kg}$ ), and recorded to the nearest $100 \mathrm{~g}$. Height was measured in a standing position without shoes, using a tape meter that was fixed to a wall, while shoulders were in a normal alignment. WC was measured at the umbilical level. Two measurements of systolic blood pressure and diastolic blood pressure were taken using a standardized mercury sphygmomanometer on the right arm, after resting for $15 \mathrm{~min}$ in a sitting position; the mean of the two measurements was considered as the participant's blood pressure. Fasting plasma glucose, HDL-cholesterol and TAG levels were measured by previously reported methods $^{(12)}$. BMI was calculated as weight (in kilograms) divided by the square of height (in metres).

\section{Definition of terms}

Abdominal obesity was defined as $W C \geq 91 \mathrm{~cm}$ for women and $\mathrm{WC} \geq 89 \mathrm{~cm}$ for men ${ }^{(13)}$. The definition of dysmetabolic state was according to the criteria for metabolic syndrome of the Joint Interim Statement ${ }^{(14)}$, with exclusion of $\mathrm{AO}$, as the presence of any three out of the following four components: (i) fasting plasma glucose $\geq 5.6 \mathrm{mmol} / \mathrm{l}(100 \mathrm{mg} / \mathrm{dl})$ or $2 \mathrm{~h}$ plasma glucose $\geq 7.8 \mathrm{mmol} / \mathrm{l}(140 \mathrm{mg} / \mathrm{dl})$ or drug treatment; (ii) fasting TAG $\geq 1.7 \mathrm{mmol} / \mathrm{l}(150 \mathrm{mg} / \mathrm{dl})$ or drug treatment; (iii) fasting HDL-cholesterol of $1.29 \mathrm{mmol} / \mathrm{l}(50 \mathrm{mg} / \mathrm{dl})$ in women and $1.03 \mathrm{mmol} / \mathrm{l}(40 \mathrm{mg} / \mathrm{dl})$ in men or drug treatment; and (iv) raised blood pressure defined as systolic blood pressure $\geq 130 \mathrm{mmHg}$, diastolic blood pressure $\geq 85 \mathrm{mmHg}$ or antihypertensive drug treatment. Data on physical activity (PA) were assessed using the Lipid Research Clinics questionnaire in the first phase of the TLGS. Due to the lack of precision of the Lipid Research Clinics questionnaire $^{(15)}$, the Modifiable Activity Questionnaire, which measures all three types of activity including leisure-time, job and household activities ${ }^{(16)}$, was used in the rest of the follow-up examinations. Since the duration of PA was not accounted for in the Lipid Research Clinics questionnaire, participants who were enrolled in the study from the first phase of the TLGS were considered 'low PA' if participating in low and moderate PA and considered 'high PA' if participating in vigorous PA for a minimum of $3 \mathrm{~d} /$ week. Individuals who entered the study at the second follow-up examination of the TLGS were defined as 'high PA' if they achieved a minimum of at least 600 MET-min/week and as 'low PA' if they had less than 600 MET-min/week (where MET is metabolic equivalent of task $)^{(17)}$. Education was classified into two groups: below diploma ( $<12$ years education); and diploma or higher ( $\geq 12$ years education). Marital status was categorized as single (including widowed) and married. A current smoker was defined as a person who smokes cigarettes daily or occasionally. Ex-smokers were considered non-smokers.

\section{Statistical analysis}

All analyses were conducted separately for men and women. Categorical variables of the baseline characteristics are expressed as $n$ and \%. Comparison of baseline characteristics between men $v$. women was done using a $\chi^{2}$ test. In the present study, the exact time of AO incidence was calculated by the interval-censored data method. Interval censoring takes account of the event happening between two time periods. Considering alternative interval-censoring approaches, results were investigated using mid-point censoring ${ }^{(18)}$. Mid-point censoring was set to the mid-point between the last negative and the most recent positive event time. End points were considered as the time of incident $\mathrm{AO}$ and censoring was defined as lost to follow-up or end of the follow-up. Cumulative incidence of $\mathrm{AO}$ with $95 \% \mathrm{CI}$ was calculated for each sex as the number of new cases of AO over the total number of individuals in that group minus half of the 
Table 1 Baseline characteristics of study participants. Tehran Lipid and Glucose Study, 1999-2014

\begin{tabular}{|c|c|c|c|c|c|c|c|}
\hline \multirow[b]{2}{*}{ Characteristic } & \multicolumn{2}{|c|}{ Total ( $n$ 5044) } & \multicolumn{2}{|c|}{ Men (n 1912) } & \multicolumn{2}{|c|}{ Women (n 3132) } & \multirow[b]{2}{*}{$P$ value } \\
\hline & $n$ & $\%$ & $n$ & $\%$ & $n$ & $\%$ & \\
\hline \multicolumn{8}{|l|}{ Age group (years) } \\
\hline $20-29$ & 1642 & $32 \cdot 6$ & 579 & $30 \cdot 3$ & 1063 & 33.9 & \multirow[t]{6}{*}{$<0.0001$} \\
\hline 30-39 & 1521 & $30 \cdot 2$ & 521 & $27 \cdot 2$ & 1000 & 31.9 & \\
\hline $40-49$ & 891 & $17 \cdot 7$ & 322 & $16 \cdot 8$ & 569 & $18 \cdot 2$ & \\
\hline $50-59$ & 528 & $10 \cdot 5$ & 228 & 11.9 & 300 & $9 \cdot 6$ & \\
\hline $60-69$ & 350 & $6 \cdot 9$ & 180 & 9.4 & 170 & $48 \cdot 6$ & \\
\hline$\geq 70$ & 112 & $2 \cdot 2$ & 82 & $4 \cdot 3$ & 30 & 1.0 & \\
\hline \multicolumn{8}{|l|}{ Educational level } \\
\hline$<12$ years & 4014 & 83.6 & 1491 & $80 \cdot 7$ & 2523 & $85 \cdot 3$ & \multirow[t]{2}{*}{$<0.0001$} \\
\hline$\geq 12$ years & 790 & $16 \cdot 4$ & 356 & $19 \cdot 3$ & 434 & $14 \cdot 7$ & \\
\hline \multicolumn{8}{|l|}{ Marital status } \\
\hline Non-married & 1236 & 24.5 & 553 & 28.9 & 683 & $21 \cdot 8$ & \multirow[t]{2}{*}{$<0.0001$} \\
\hline Married & 3808 & $75 \cdot 5$ & 1359 & $71 \cdot 1$ & 2449 & $78 \cdot 2$ & \\
\hline \multicolumn{8}{|l|}{ BMI group $\left(\mathrm{kg} / \mathrm{m}^{2}\right)$} \\
\hline $18 \cdot 5-21.5$ & 973 & $20 \cdot 5$ & 514 & $27 \cdot 3$ & 459 & $16 \cdot 1$ & \multirow[t]{4}{*}{$<0.0001$} \\
\hline $21 \cdot 5-25 \cdot 0$ & 2073 & $43 \cdot 7$ & 993 & $52 \cdot 7$ & 1080 & $37 \cdot 8$ & \\
\hline $25 \cdot 0-27 \cdot 5$ & 1175 & $24 \cdot 8$ & 349 & 18.5 & 826 & 28.9 & \\
\hline $27 \cdot 5-30 \cdot 0$ & 518 & $10 \cdot 9$ & 29 & 1.5 & 489 & $17 \cdot 1$ & \\
\hline \multicolumn{8}{|l|}{ Dysmetabolic state } \\
\hline No & 4167 & $86 \cdot 9$ & 1580 & $87 \cdot 3$ & 2587 & $86 \cdot 6$ & \multirow[t]{2}{*}{0.515} \\
\hline Yes & 629 & $13 \cdot 1$ & 230 & $12 \cdot 7$ & 399 & $13 \cdot 4$ & \\
\hline \multicolumn{8}{|l|}{ Physical activity* } \\
\hline Low & 3337 & $70 \cdot 0$ & 1316 & $71 \cdot 8$ & 2021 & $68 \cdot 8$ & \multirow[t]{2}{*}{0.026} \\
\hline High & 1433 & $30 \cdot 0$ & 516 & $28 \cdot 2$ & 917 & 31.2 & \\
\hline \multicolumn{8}{|l|}{ Smoking status } \\
\hline Non-smoker & 4349 & $87 \cdot 3$ & 1344 & $71 \cdot 1$ & 3005 & $97 \cdot 2$ & \multirow[t]{2}{*}{$<0.0001$} \\
\hline Current smoker & 631 & $12 \cdot 7$ & 545 & 28.9 & 86 & $2 \cdot 8$ & \\
\hline
\end{tabular}

*Physical activity measured by the Lipid Research Clinics questionnaire and the Modifiable Activity Questionnaire.

censored population. The person-year method was used to obtain $\mathrm{AO}$ incidence rates, which are reported as the number of cases per 1000 person-years. Cox proportional hazard modelling was used to estimate unadjusted and age-adjusted hazard ratios (HR) along with $95 \%$ CI for baseline groups of BMI, PA, dysmetabolic state, educational level, smoking status and marital status. The proportionality assumption was verified by assessing the correlation between the Schoenfield residuals and persondays along with observing log minus log plots (considering different groups as strata variables). All analyses were performed using the statistical software packages IBM SPSS for Windows version 20 and Stata version 12 SE, with a two-tailed $P$ values of 0.05 being considered significant.

\section{Results}

In the present study, 5044 participants (37\% male), with mean age of 37.7 (SD 13.5) years, mean BMI of 24.3 (SD 3.1) $\mathrm{kg} / \mathrm{m}^{2}\left(23.0(\mathrm{SD} 2.4)\right.$ and $25.0(\mathrm{sD} 3.2) \mathrm{kg} / \mathrm{m}^{2}$ for men and women, respectively) and mean WC of 79.8 (SD 6.8$) \mathrm{cm}(80.2$ (SD 5.8) and 79.5 (SD 7.4) cm for men and women, respectively) at baseline, were followed for a median of 6 years (25th-75th percentile: 2-10 years). Baseline characteristics of the participants are shown in Table 1. In addition, regarding individual components of dysmetabolic state, 1602 (32.3\%) had high TAG, 3334 (67.1\%) had low HDL-cholesterol, 1043 (20.7\%) had high blood pressure and 674 (13.4\%) had high fasting plasma glucose.

Men had significantly less PA and a higher frequency of smoking than women at baseline. There was no significant difference between the sexes in prevalence of dysmetabolic state.

During follow-up, 3093 subjects (1720 women) developed AO that led to a cumulative incidence of $76.02(95 \%$ CI $74.70,77.32) \%$. Total cumulative incidence of AO was 70.90 (95\% CI 69.08, 72.69$) \%$ for women and 83.59 (95\% CI $81 \cdot 76,85 \cdot 34) \%$ for men.

Incidence rate in the whole population was $96.0(95 \% \mathrm{CI}$ $92 \cdot 7,99 \cdot 5)$ per 1000 person-years. Corresponding incidence rates among men and women were 138.7 (95\% CI 131.5, $146.3)$ and $77.1(95 \%$ CI $73.5,80.9)$ per 1000 person-years. The highest incidence rate in women was 146.3 (128.1, $167.0)$ per 1000 person-years in the 50-59 years age group and in men was $152.6(138 \cdot 2,168 \cdot 5)$ per 1000 person-years in the 30-39 years age group. Median survival for men was 4 (SD 2.8) years $v .7$ (SD 3.1) years for women.

The association of different risk factors with developing incident $\mathrm{AO}$ from clinical and demographic predictors is presented in Table 2 (men) and Table 3 (women).

Dysmetabolic state and BMI were significantly associated with increasing incident AO in both sexes. Higher educational level in men significantly increased the risk of 
Table 2 Cumulative incidence, hazard ratios and incidence rate of potential risk factors of abdominal obesity in men. Tehran Lipid and Glucose Study, 1999-2014

\begin{tabular}{|c|c|c|c|c|c|c|c|c|}
\hline Characteristic & $\begin{array}{l}\text { Cumulative } \\
\text { incidence }\end{array}$ & $95 \% \mathrm{Cl}$ & $\mathrm{HR}$ & $95 \% \mathrm{Cl}$ & $\begin{array}{c}\text { Age-adjusted } \\
\text { HR }\end{array}$ & $95 \% \mathrm{Cl}$ & $\begin{array}{l}\text { IR (per } 1000 \\
\text { person-years) }\end{array}$ & $95 \% \mathrm{Cl}$ \\
\hline \multicolumn{9}{|c|}{ Age group (years) } \\
\hline $20-29$ & 0.86 & $0.83,0.89$ & 1.00 & Ref. & - & - & $146 \cdot 5$ & $133 \cdot 5,160 \cdot 8$ \\
\hline 30-39 & 0.86 & $0.83,0.89$ & 1.05 & $0.92,1.21$ & - & - & $152 \cdot 6$ & $138.2,168.5$ \\
\hline $40-49$ & 0.80 & $0.75,0.85$ & 0.85 & $0.72,1.00$ & - & - & 121.4 & $106 \cdot 3,138 \cdot 8$ \\
\hline $50-59$ & $0 \cdot 80$ & $0.74,0.85$ & 0.87 & $0.72,1.05$ & - & - & $125 \cdot 0$ & $106 \cdot 6,146 \cdot 5$ \\
\hline $60-69$ & 0.77 & $0.70,0.83$ & 0.88 & $0.72,1.09$ & - & - & $121 \cdot 2$ & $100 \cdot 6,146 \cdot 1$ \\
\hline$\geq 70$ & $0 \cdot 73$ & $0.62,0.83$ & 1.00 & $0.78,1.42$ & - & - & 149.6 & $112 \cdot 4,199 \cdot 2$ \\
\hline \multicolumn{9}{|c|}{ Educational level } \\
\hline$<12$ years & 0.83 & $0.81,0.85$ & 1.00 & Ref. & 1.00 & Ref. & $134 \cdot 7$ & $126 \cdot 8,143 \cdot 1$ \\
\hline$\geq 12$ years & $0 \cdot 87$ & $0.83,0.91$ & $1 \cdot 20$ & $1.05,1.37$ & $1 \cdot 2$ & $1.05,1.37$ & 163.2 & $145 \cdot 0,183.6$ \\
\hline \multicolumn{9}{|l|}{ Marital status } \\
\hline Non-married & 0.86 & $0.82,0.89$ & 1.00 & Ref. & 1.00 & Ref. & 143.6 & $130 \cdot 4,158 \cdot 1$ \\
\hline Married & 0.82 & $0.80,0.84$ & 0.97 & $0.87,1.09$ & 0.99 & $0.99,1.00$ & $136 \cdot 6$ & $128 \cdot 1,145 \cdot 6$ \\
\hline \multicolumn{9}{|c|}{ BMI group $\left(\mathrm{kg} / \mathrm{m}^{2}\right)$} \\
\hline 18.5-21.5 & 0.62 & $0.57,0.67$ & 1.00 & Ref. & 1.00 & Ref. & $60 \cdot 0$ & $52 \cdot 8,68 \cdot 3$ \\
\hline $21 \cdot 5-25 \cdot 0$ & 0.87 & $0.85,0.89$ & $2 \cdot 70$ & $2 \cdot 30,3 \cdot 10$ & $2 \cdot 80$ & $2 \cdot 40,3 \cdot 20$ & 164.4 & $153 \cdot 2,176.5$ \\
\hline $25 \cdot 0-27 \cdot 5$ & 0.96 & $0.94,0.98$ & $5 \cdot 10$ & $4 \cdot 30,6 \cdot 00$ & $5 \cdot 20$ & $4 \cdot 40,6 \cdot 20$ & $301 \cdot 8$ & $270 \cdot 5,336 \cdot 8$ \\
\hline $27 \cdot 5-30 \cdot 0$ & 0.96 & $0.84,0.99$ & $4 \cdot 20$ & $2 \cdot 80,6 \cdot 30$ & $4 \cdot 20$ & $2 \cdot 80,6 \cdot 30$ & 264.7 & $181 \cdot 5,385.9$ \\
\hline \multicolumn{9}{|c|}{ Dysmetabolic state } \\
\hline No & 0.83 & $0.81,0.85$ & 1.00 & Ref. & 1.00 & Ref. & 133.7 & $126 \cdot 1,141 \cdot 8$ \\
\hline Yes & 0.88 & $0.83,0.92$ & $1 \cdot 34$ & $1.15,1.57$ & 1.38 & $1.17,1.61$ & $182 \cdot 5$ & $157 \cdot 7,211 \cdot 2$ \\
\hline \multicolumn{9}{|c|}{ Physical activity* } \\
\hline Low & 0.84 & $0.82,0.86$ & 1.00 & Ref. & 1.00 & Ref. & 141.9 & $133 \cdot 2,151 \cdot 1$ \\
\hline High & $0 \cdot 80$ & $0.77,0.84$ & 0.92 & $0.82,1.00$ & 0.92 & $0.81,1.00$ & $131 \cdot 1$ & $118 \cdot 0,145 \cdot 7$ \\
\hline \multicolumn{9}{|l|}{ Smoking status } \\
\hline Non-smoker & 0.84 & $0.82,0.86$ & 1.00 & Ref. & 1.00 & Ref. & $142 \cdot 5$ & $133 \cdot 8,151 \cdot 7$ \\
\hline $\begin{array}{l}\text { Current } \\
\text { smoker }\end{array}$ & 0.81 & $0.77,0.84$ & 0.90 & $0 \cdot 80,1.01$ & 0.90 & $0.80,1.01$ & $128 \cdot 4$ & $115 \cdot 9,142 \cdot 2$ \\
\hline
\end{tabular}

Cumulative incidence $=$ number of incident obesity cases divided by the total number of individuals; HR, hazard ratio; IR, incidence rate = number of incident obesity cases divided by the person-years of follow-up; Ref., reference category.

${ }^{*}$ Physical activity measured by the Lipid Research Clinics questionnaire and the Modifiable Activity Questionnaire.

$\mathrm{AO}$, in contrast to women $(\mathrm{HR}=1 \cdot 20 ; 95 \% \mathrm{CI} 1 \cdot 05,1.37$ in men and $\mathrm{HR}=0.67 ; 95 \% \mathrm{CI} 0.57,0.78$ in women). Ageing was significantly associated with $\mathrm{AO}$ in women, with the highest $\mathrm{HR}$ in the 50-59 years age group ( $\mathrm{HR}=3 \cdot 19 ; 95 \%$ CI $2 \cdot 70,3 \cdot 75$ ).

Married status was a significant risk factor of developing $\mathrm{AO}$ in women, whereas marital status in men was not significantly associated with AO. Smoking status and PA were not among predictors of $\mathrm{AO}$, in men or women.

\section{Discussion}

After a median of 6 years of follow-up, the present study indicated high incidence of $\mathrm{AO}$ in an urban adult Tehranian population, which was higher among men than women $(83.5 v \cdot 70.9 \%)$. Important risk factors of developing $\mathrm{AO}$ at baseline were dysmetabolic state and BMI in both sexes, high educational level and less PA in men, and married status in women. Moreover, men mostly developed AO earlier than women (30-39 v. 50-59 years).

There are limited studies investigating the incidence of $\mathrm{AO}$ worldwide, which differ in terms of the mean age of subjects, socio-economic status, WC cut-offs and length of follow-up. Haftenberger et al. reported a high rate of AO within 10 years among adults, by including the data of 15444 men and 17207 women from seven prospective cohort studies in Germany. The rate of progression to $\mathrm{AO}$ in participants with low baseline WC $(<94 \mathrm{~cm}$ in men; $<80 \mathrm{~cm}$ in women) was reported near to $20 \%$. Moreover, this rate was higher (50\%) among participants with intermediate WC (94-102 cm in men; $80-88 \mathrm{~cm}$ in women) at baseline ${ }^{(19)}$. Another study from Europe reported ageadjusted incidence of $\mathrm{AO}$ in an urban Portuguese population to be 59.7 and 23.8 per 1000 person-years for women and men, respectively ${ }^{(20)}$, which was lower than that of our population. In Iran, as a middle-income country, we found higher incidence of $\mathrm{AO}$ as compared with both above-mentioned results from high-income countries. Rising trends of non-communicable diseases including obesity and AO have been reported in low- and middle-income countries during recent years ${ }^{(21)}$. In fact, industrialization and alterations in occupations and transportation systems cause changes in nutrition pattern ${ }^{(22)}$. According to studies conducted in China, AO has increased dramatically from $12 \%$ in 1993 to $21 \%$ in 2009 in people with normal BMI, specifically in men. Interestingly, this rising trend was observed in both sexes, rural and urban areas, all ages and education groups ${ }^{(23)}$. In Iran as a 
Table 3 Cumulative incidence, hazard ratios and incidence rate of potential risk factors of abdominal obesity in women. Tehran Lipid and Glucose Study, 1999-2014

\begin{tabular}{|c|c|c|c|c|c|c|c|c|}
\hline Characteristic & $\begin{array}{l}\text { Cumulative } \\
\text { incidence }\end{array}$ & $95 \% \mathrm{Cl}$ & $\mathrm{HR}$ & $95 \% \mathrm{Cl}$ & $\begin{array}{c}\text { Age-adjusted } \\
\text { HR }\end{array}$ & $95 \% \mathrm{Cl}$ & $\begin{array}{l}\text { IR (per } 1000 \\
\text { person-years) }\end{array}$ & $95 \% \mathrm{Cl}$ \\
\hline \multicolumn{9}{|c|}{ Age group (years) } \\
\hline $20-29$ & 0.56 & $0.52,0.59$ & 1.00 & Ref. & - & - & $46 \cdot 8$ & $42 \cdot 5,51 \cdot 5$ \\
\hline $30-39$ & 0.72 & $0.69,0.75$ & 1.66 & $1.46,1.88$ & - & - & 77.9 & $71 \cdot 8,84 \cdot 6$ \\
\hline $40-49$ & 0.81 & $0.77,0.84$ & 2.45 & $2 \cdot 13,2 \cdot 81$ & - & - & 112.6 & $101.9,124.4$ \\
\hline $50-59$ & 0.80 & $0.74,0.85$ & $3 \cdot 19$ & $2 \cdot 70,3 \cdot 75$ & - & - & $146 \cdot 3$ & $128.1,167 \cdot 0$ \\
\hline $60-69$ & 0.75 & $0.68,0.82$ & $2 \cdot 38$ & $1.92,2.96$ & - & - & 109.8 & $90 \cdot 5,133 \cdot 2$ \\
\hline$\geq 70$ & 0.69 & $0.50,0.86$ & $2 \cdot 62$ & $1.59,4.33$ & - & - & $112 \cdot 7$ & $67.9,187.0$ \\
\hline \multicolumn{9}{|c|}{ Educational level } \\
\hline$<12$ years & 0.72 & $0.70,0.74$ & 1.00 & Ref. & 1.00 & Ref. & 79.7 & $75 \cdot 7,84 \cdot 0$ \\
\hline$\geq 12$ years & 0.60 & $0.55,0.66$ & 0.67 & $0.57,0.78$ & 0.76 & $0.65,0.88$ & $54 \cdot 1$ & $46 \cdot 9,62 \cdot 4$ \\
\hline \multicolumn{9}{|l|}{ Marital status } \\
\hline Non-married & 0.56 & $0.52,0.61$ & 1.00 & Ref. & 1.00 & Ref. & $50 \cdot 6$ & $44 \cdot 9,57 \cdot 1$ \\
\hline Married & 0.74 & $0.72,0.76$ & 1.68 & $1.48,1.92$ & 1.51 & $1.32,1.72$ & $85 \cdot 3$ & $81 \cdot 0,89 \cdot 8$ \\
\hline \multicolumn{9}{|c|}{ BMI group $\left(\mathrm{kg} / \mathrm{m}^{2}\right)$} \\
\hline $18.5-21.5$ & 0.28 & $0.23,0.34$ & 1.00 & Ref. & 1.00 & Ref. & $17 \cdot 4$ & $13 \cdot 9,21 \cdot 7$ \\
\hline $21 \cdot 5-25 \cdot 0$ & 0.60 & $0.56,0.63$ & 3.02 & $2 \cdot 37,3.85$ & 2.63 & $2.06,3.35$ & 51.4 & $46 \cdot 9,56 \cdot 3$ \\
\hline $25 \cdot 0-27 \cdot 5$ & 0.80 & $0.77,0.83$ & 6.38 & $5 \cdot 02,8 \cdot 10$ & 5.45 & $4.28,6.93$ & 104.8 & $96.4,113.9$ \\
\hline $27 \cdot 5-30 \cdot 0$ & 0.91 & $0.88,0.93$ & $11 \cdot 27$ & $8 \cdot 80,14.30$ & $9 \cdot 50$ & $7 \cdot 42,12 \cdot 10$ & $177 \cdot 6$ & $161 \cdot 1,195 \cdot 7$ \\
\hline \multicolumn{9}{|c|}{ Dysmetabolic state } \\
\hline No & 0.69 & $0.67,0.71$ & 1.00 & Ref. & 1.00 & Ref. & $72 \cdot 3$ & $68 \cdot 6,76 \cdot 2$ \\
\hline \multirow{2}{*}{\multicolumn{9}{|c|}{ Physical activity* }} \\
\hline & & & & & & & & \\
\hline Low & 0.72 & $0.70,0.74$ & 1.00 & Ref. & 1.00 & Ref. & $77 \cdot 8$ & $73 \cdot 4,82.5$ \\
\hline High & 0.70 & $0.66,0.73$ & 0.98 & $0.88,1.09$ & 0.98 & $0.88,1.09$ & $76 \cdot 8$ & $70 \cdot 3,84 \cdot 0$ \\
\hline \multicolumn{9}{|l|}{ Smoking status } \\
\hline Non-smoker & 0.70 & $0.69,0.72$ & 1.00 & Ref. & 1.00 & Ref. & $77 \cdot 0$ & $73 \cdot 4,80 \cdot 8$ \\
\hline $\begin{array}{l}\text { Current } \\
\text { smoker }\end{array}$ & 0.74 & $0.63,0.84$ & $1 \cdot 11$ & $0 \cdot 84,1.47$ & 0.99 & $0.75,1.32$ & $86 \cdot 2$ & $65 \cdot 5,113.5$ \\
\hline
\end{tabular}

Cumulative incidence $=$ number of incident obesity cases divided by the total number of individuals; HR, hazard ratio; IR, incidence rate $=$ number of incident obesity cases divided by the person-years of follow-up; Ref., reference category.

*Physical activity measured by the Lipid Research Clinics questionnaire and the Modifiable Activity Questionnaire.

developing country, low PA, sedentary lifestyle, changes in diets and higher energy intake are suggested to play key roles in this alarming rise in incidence of $\mathrm{AO}^{(24,25)}$.

The causes of developing $\mathrm{AO}$ are multifactorial, including PA, education, marital status, socio-economic status and smoking ${ }^{(26)}$. As a key factor to burn off excess energy, PA is consistently associated with lower risk of $\mathrm{AO}^{(27,28)}$. In our study, males with a high level of PA were at lower risk of $\mathrm{AO}$. As our females mostly became abdominally obese during 50-59 years of age, the absence of an association between baseline PA and developing $\mathrm{AO}$ could be related to the hormonal changes during menopause, as fat distribution in women results in $\mathrm{AO}$ during this period ${ }^{(29)}$. Moreover, we found dysmetabolic state to be a risk factor for developing AO. Previous studies revealed that metabolic syndrome components in healthy people can independently predict the incidence of metabolic syndrome itself. Therefore, it could be anticipated that people with an unhealthy metabolic status would be at risk of developing $\mathrm{AO}$ as a key component of the metabolic syndrome ${ }^{(30,31)}$. Moreover, it has been shown that individuals with unhealthy metabolic status without $\mathrm{AO}$ are at increased risk of cardiovascular events, compared with non-abdominally obese and healthy metabolic individuals ${ }^{(32,33)}$.
Moreover, high educational level has been proposed as a protective factor for developing AO mostly in women ${ }^{(34)}$. Likewise, in our study, women with high education levels were at lower risk of AO. Additionally, differences in the incidence of $\mathrm{AO}$ between age groups and sexes were depicted in our results by the large proportion of men aged 30-39 years who developed AO; this could be attributed to the high energy density and protein intakes of young men ${ }^{(35)}$. In contrast, young females did not develop $\mathrm{AO}$, which could be a result of the importance of healthy diets to young women because of their higher educational level and health programmes focusing on women's health in recent years ${ }^{(36,37)}$.

Studies have reported diverse kinds of associations of AO with marital status. In a Greek investigation of both men and women, those with married status were at higher risk of $\mathrm{AO}^{(38)}$. However, an Iranian study reported this association only for married women, not men ${ }^{(8)}$. Our findings are in agreement with these studies about women, but not men. Interestingly, another report highlights the importance of transition into or out of marriage in cohort studies and the risk of $\mathrm{AO}^{(39)}$. Therefore, since marital status was not tracked in our study, we have to be cautious about interpreting our findings in this regard. 
Although both smoking and amount of smoking are reported to be positively associated with developing $\mathrm{AO}^{(40-42)}$, we found no such an association in our study. Several possible reasons for this unexplained finding can be suggested, including behavioural changes in individuals which led to quitting smoking ${ }^{(12)}$ and lack of information regarding the dose-response relationship between smoking and development of $\mathrm{AO}$.

Finally, a number of potential shortcomings in our study have to be considered. First, the TLGS is a cohort study conducted on urban Tehranians. Therefore, our results could not be generalized to the whole Iranian population, especially rural areas. Second, we used umbilicus level instead of midpoint for measurement of WC. It has been reported that WC measurement at midpoint is slightly lower than WC measurement at umbilicus and may influence the prevalence of $\mathrm{AO}$. Therefore, the high incidence of $\mathrm{AO}$ in our report can, in part, be explained by this measurement ${ }^{(43,44)}$. Third, some important risk factors for incidence of AO such as dietary habits and socio-economic status were not taken into account. In addition, we measured all possible risk factors at a single time point at the beginning of the study; however, similar to us, most epidemiological studies in this field have provided single-point measurements for possible risk factors. The present study has its own strengths as well; to the best of our knowledge, it is one of the few populationbased studies with an intermediate length of followup that evaluates the sex-stratified incidence of $\mathrm{AO}$ and its risk factors. We also used measured data for anthropometric parameters, rather than selfreported data.

Future studies on the current topic are required to investigate the effect over longer follow-ups, tracking changes of risk factors by repeated measurements and including the impact of nutrition, socio-economic and menopausal status on the incidence of AO. The evidence from the present study implies that in a large metropolitan city of a developing country, over a median follow-up of 6 years, the incidence of $\mathrm{AO}$ is high especially among young men, which requires that current health priorities and strategies should target this age group to provide effective prevention. Moreover, we recommend more focus on screening the general population for dysmetabolic state as an outstanding risk factor for developing $\mathrm{AO}$ in both sexes.

\section{Acknowledgements}

Acknowledgements: The authors express their appreciation to participants of District 13, Tehran, for their enthusiastic support in this study. Financial support: This research received no specific grant from any funding agency in the public, commercial or not-for-profit sectors.
Conflict of interest: None. Authorship: M.B., M.V., F.A. and F.H. designed the study. M.B., S.S. and Z.P. collected and analysed the data and drafted the manuscript. F.H. and M.V. critically reviewed the paper and edited the manuscript. F.H. supervised and F.A. advised throughout the study. Ethics of human subject participation: The protocol of the present study, conducted in accordance with principles of the Declaration of Helsinki, was approved by the ethics committee of the Research Institute of Endocrine Sciences of Shahid Beheshti University of Medical Sciences. All participants provided written, informed consent.

\section{References}

1. Kumanyika SK, Obarzanek E, Stettler N et al. (2008) Population-based prevention of obesity: the need for comprehensive promotion of healthful eating, physical activity, and energy balance: a scientific statement from American Heart Association Council on Epidemiology and Prevention, Interdisciplinary Committee for Prevention (formerly the Expert Panel on Population and Prevention Science). Circulation 118, 428-464.

2. Barroso M, Goday A, Ramos R et al. (2018) Interaction between cardiovascular risk factors and body mass index and 10-year incidence of cardiovascular disease, cancer death, and overall mortality. Prev Med 107, 81-89.

3. Hosseinpanah F, Mirbolouk M, Mossadeghkhah A et al. (2016) Incidence and potential risk factors of obesity among Tehranian adults. Prev Med 82, 99-104.

4. Han TS \& Lean ME (2016) A clinical perspective of obesity, metabolic syndrome and cardiovascular disease. JRSM Cardiovas Dis 5, 2048004016633371.

5. Mainous AG 3rd, Tanner RJ, Jo A et al. (2016) Prevalence of prediabetes and abdominal obesity among healthy-weight adults: 18-year trend. Ann Fam Med 14, 304-310.

6. Ford ES, Maynard LM \& Li C (2014) Trends in mean waist circumference and abdominal obesity among US adults, 1999-2012. JAMA 312, 1151-1153.

7. Azizi F, Salehi P, Etemadi A et al. (2003) Prevalence of metabolic syndrome in an urban population: Tehran Lipid and Glucose Study. Diabetes Res Clin Pract 61, 29-37.

8. Barzin M, Keihani S, Hosseinpanah F et al. (2015) Rising trends of obesity and abdominal obesity in 10 years of follow-up among Tehranian adults: Tehran Lipid and Glucose Study (TLGS). Public Health Nutr 18, 2981-2989.

9. Zhang C, Rexrode KM, van Dam RM et al. (2008) Abdominal obesity and the risk of all-cause, cardiovascular, and cancer mortality: sixteen years of follow-up in US women. Circulation 117, 1658-1667.

10. Fan H, Li X, Zheng L et al. (2016) Abdominal obesity is strongly associated with cardiovascular disease and its risk factors in elderly and very elderly community-dwelling Chinese. Sci Rep 6, 21521.

11. Azizi F, Rahmani M, Emami H et al. (2002) Cardiovascular risk factors in an Iranian urban population: Tehran Lipid and Glucose Study (phase 1). Soz Praventivmed 47, 408-426.

12. Azizi F, Ghanbarian A, Momenan AA et al. (2009) Prevention of non-communicable disease in a population in nutrition transition: Tehran Lipid and Glucose Study phase II. Trials 10, 5 .

13. Delavari A, Forouzanfar MH, Alikhani S et al. (2009) First nationwide study of the prevalence of the metabolic syndrome and optimal cutoff points of waist circumference in the Middle East: the national survey of risk factors for 
noncommunicable diseases of Iran. Diabetes Care $\mathbf{3 2}$, 1092-1097.

14. Alberti KG, Zimmet P \& Shaw J (2006) Metabolic syndrome - a new world-wide definition. A consensus statement from the International Diabetes Federation. Diabet Med 23, 469-480.

15. Ainsworth BE, Jacobs DR Jr \& Leon AS (1993) Validity and reliability of self-reported physical activity status: the Lipid Research Clinics questionnaire. Med Sci Sport Exerc 25, 92-98.

16. Kriska AM, Knowler WC, LaPorte RE et al. (1990) Development of questionnaire to examine relationship of physical activity and diabetes in Pima Indians. Diabetes Care $\mathbf{1 3}$ 401-411.

17. IPAQ Research Committee (2005) Guidelines for Data Processing and Analysis of the International Physical Activity Questionnaire (IPAQ) - Short and Long Forms. https:// www.researchgate.net/file.PostFileLoader.html?id=5641f4 c36143250eac8b45b7\&assetKey=AS\%3A294237418606593\% 401447163075131 (accessed November 2005).

18. Lindsey JC \& Ryan LM (1998) Tutorial in biostatistics methods for interval-censored data. Stat Med 17, 219-238.

19. Haftenberger M, Mensink GB, Vogt S et al. (2016) Changes in waist circumference among German adults over time compiling results of seven prospective cohort studies. Obes Facts 9, 332-343.

20. Camoes M, Lopes C, Oliveira A et al. (2010) Overall and central obesity incidence in an urban Portuguese population. Prev Med 50, 50-55.

21. Reddy KS (2002) Cardiovascular diseases in the developing countries: dimensions, determinants, dynamics and directions for public health action. Public Health Nutr 5, 231-237.

22. Hosseinpanah F, Barzin M, Eskandary PS et al. (2009) Trends of obesity and abdominal obesity in Tehranian adults: a cohort study. BMC Public Health 9, 426.

23. Du T, Sun X, Yin P et al. (2013) Increasing trends in central obesity among Chinese adults with normal body mass index, 1993-2009. BMC Public Health 13, 327.

24. Ghassemi H, Harrison G \& Mohammad K (2002) An accelerated nutrition transition in Iran. Public Health Nutr $\mathbf{5}$, 149-155.

25. Koohpayehzadeh J, Etemad K, Abbasi M et al. (2014) Gender-specific changes in physical activity pattern in Iran: national surveillance of risk factors of noncommunicable diseases (2007-2011). Int J Public Health 59, 231-241.

26. Koh-Banerjee P, Chu NF, Spiegelman D et al. (2003) Prospective study of the association of changes in dietary intake, physical activity, alcohol consumption, and smoking with 9-y gain in waist circumference among 16587 US men. Am J Clin Nutr 78, 719-727.

27. Lopez-Sobaler AM, Rodriguez-Rodriguez E, ArancetaBartrina J et al. (2016) General and abdominal obesity Is related to physical activity, smoking and sleeping behaviours and mediated by the educational level: findings from the ANIBES study in Spain. PLoS One 11, e0169027.

28. Fam B, Amouzegar A, Arzhan S et al. (2013) Association between physical activity and metabolic risk factors in adolescents: Tehran Lipid and Glucose Study. Int J Prev Med 4, 1011-1017.
29. Poehlman ET (2002) Menopause, energy expenditure, and body composition. Acta Obstet Gynecol Scand 81, 603-611.

30. Heidari Z, Hosseinpanah F, Mehrabi Y et al. (2010) Predictive power of the components of metabolic syndrome in its development: a 6.5-year follow-up in the Tehran Lipid and Glucose Study (TLGS). Eur J Clin Nutr 64, 1207-1214.

31. Cheung BM, Wat NM, Tam S et al. (2008) Components of the metabolic syndrome predictive of its development: a 6-year longitudinal study in Hong Kong Chinese. Clin Endocrinol (Oxf) 68, 730-737.

32. Keihani S, Hosseinpanah F, Barzin M et al. (2015) Abdominal obesity phenotypes and risk of cardiovascular disease in a decade of follow-up: the Tehran Lipid and Glucose Study. Atherosclerosis 238, 256-263.

33. van der AD, Nooyens AC, van Duijnhoven FJ et al. (2014) All-cause mortality risk of metabolically healthy abdominal obese individuals: the EPIC-MORGEN study. Obesity (Silver Spring) 22, 557-564.

34. Hajian-Tilaki KO \& Heidari B (2010) Association of educational level with risk of obesity and abdominal obesity in Iranian adults. J Public Health (Oxf) 32, 202-209.

35. Bahadoran Z, Mirmiran P, Golzarand M et al. (2012) Fast food consumption in Iranian adults; dietary intake and cardiovascular risk factors: Tehran Lipid and Glucose Study. Arch Iran Med 15, 346-351.

36. Ramezani Tehrani F, Bahri M, Gholami R et al. (2014) Secular trend of menopausal age and related factors among Tehrani women born from 1930 to 1960; Tehran Lipid and Glucose Study. Arch Iran Med 17, 406-410.

37. Joulaei H, Maharlouei N, Lankarani KB et al. (2016) Narrative review of women's health in Iran: challenges and successes. Int J Equity Health 15, 25.

38. Tzotzas T, Vlahavas G, Papadopoulou SK et al. (2010) Marital status and educational level associated to obesity in Greek adults: data from the National Epidemiological Survey. BMC Public Health 10, 732.

39. Hosseinpour-Niazi S, Mirmiran $\mathrm{P}$, Hosseinpanah $\mathrm{F}$ et al. (2014) Association of marital status and marital transition with metabolic syndrome: Tehran Lipid and Glucose Study. Int J Endocrinol Metab 12, e18980.

40. Saarni SE, Pietilainen K, Kantonen S et al. (2009) Association of smoking in adolescence with abdominal obesity in adulthood: a follow-up study of 5 birth cohorts of Finnish twins. Am J Public Health 99, 348-354.

41. Fujiyoshi A, Miura K, Kadowaki S et al. (2016) Lifetime cigarette smoking is associated with abdominal obesity in a community-based sample of Japanese men: the Shiga Epidemiological Study of Subclinical Atherosclerosis (SESSA). Prev Med Rep 4, 225-232.

42. Kim JH, Shim KW, Yoon YS et al. (2012) Cigarette smoking increases abdominal and visceral obesity but not overall fatness: an observational study. PLoS One 7, e45815.

43. Bosy-Westphal A, Booke CA, Blocker T et al. (2010) Measurement site for waist circumference affects its accuracy as an index of visceral and abdominal subcutaneous fat in a Caucasian population. J Nutr 140, 954-961.

44. Mason C \& Katzmarzyk PT (2009) Effect of the site of measurement of waist circumference on the prevalence of the metabolic syndrome. Am J Cardiol 103, 1716-1720. 